\title{
Industrial Internet of Things as a Challenge for Higher Education
}

\author{
Corneliu Octavian Turcu ${ }^{1}$ \\ Computers, Electronics and Automation Department \\ Stefan cel Mare University of Suceava \\ Suceava, Romania
}

\author{
Cristina Elena Turcu ${ }^{2}$ \\ Computers Department \\ Stefan cel Mare University of Suceava \\ Suceava, Romania
}

\begin{abstract}
This paper is aimed to examine the adoption of the Internet of Things (IoT) in industry (so-called Industrial Internet of Things, shortly IIoT) and the requirements for higher education in the times of the fourth industrial revolution. The addition of the fourth letter, "I" in front of the "IoT" coins the name of the new concept, "IIoT" in relation with another term, "Industry 4.0". Because these concepts have no precise and widely accepted definitions, we presented some considered relevant by scientific literature. The paper also highlights the most important similarities and differences between these concepts. IIoT is a very dynamic concept and it will constantly bring changes in digital technologies, requirements and markets, and will also transform industries and business practices. According to manifold studies, currently, there is a skill gap which may widen in the future if no action is taken. Higher education must adopt the latest related technologies and must adapt to the new ways in which people, machines, services and data can interact. Consequently, employees, students, graduates, etc. have to be equally dynamic in learning and acquiring new skills. The transition from higher education to employment is a challenge that could be more easily addressed through the efforts of all stakeholders, from individuals to organizations, and from businesses to governments. As changes in higher education take time, all stakeholders will now have to act in preparing for the Industrial Internet of Things.
\end{abstract}

Keywords-Industry 4.0; Industrial Internet of Things; Internet of Things; higher education; skills gap

\section{INTRODUCTION}

Industrial engineering is constantly bound to adapt to the many occurring changes, from progress in business models to the most advanced information and communications technologies; the purpose is to increase the overall quality of products and productivity, and also to reduce overall costs. Currently, we are witnessing the rise of a new digital industrial wave, namely the fourth industrial revolution (IR 4.0 or FIR), enabled by the widespread deployment of inexpensive smart sensors, processors, wireless sensor networks, embedded systems, but also by the advances in data storage, analytics, cloud infrastructure, and so on. Various worldwide surveys conducted in relation to the industry field reveal that the biggest current technological initiative for implementing this revolution is the Industrial Internet of Things (IIoT).

In a report [1], Accenture estimates that the Industrial Internet of Things could add $\$ 14.2$ trillion to the global economy by 2030. The global Industrial Internet of Things market is anticipated to expand at a CAGR of $+24 \%$ during the 2018-2022 [2]. A McKinsey report [3] anticipates that by 2025, the percentage of factories adopting IIoT will reach $65 \%-90 \%$ in advanced economies and $50 \%-70 \%$ in developing economies.

Researchers estimate that the IIoT development will impact different sectors, influencing both the industry and the labor market, leading to the creation of new jobs, but also to the elimination of some existing ones. Thus, various studies on technology uptake conducted in different countries reveal that the adoption of new technologies is expected to have a significant impact on the employment landscape. For example, according to [4], "in many industries and countries, the most in-demand occupations or specialties did not exist 10 or even five years ago, and the pace of change is set to accelerate". The same report estimates that " $65 \%$ of children entering primary school today will ultimately end up working in completely new job types that don't yet exist". This is also the case of the Industrial Internet of Things. Various publications have focused their attention on this new concept, analyzing, among others, both the multiple possible benefits and challenges generated by the application of this paradigm across different economies. In addition to the technological barriers, the widespread and accelerated adoption of the Internet of Things (IoT) paradigm in the industrial field is hampered by the skills gap. According to manifold studies, currently, there is a skills gap which may widen in the future if no action is taken. For example, an analysis from Deloitte [5] reveals that over the next decade, there will be 3.5 million job openings in manufacturing, but only enough skilled labor to fill less than half of them. And as IIoT growth takes hold, the need for skilled workforce will intensify. One solution to reduce the skills gap lies in education, for example through effective skills, re- and up-skilling programmes. IIoT is a very dynamic concept and it will constantly bring changes in digital technologies, requirements and markets, and will also transform industries and business practices. Consequently, employees, students, graduates, etc. have to be equally dynamic in learning and acquiring new skills. Higher education must adopt the latest related technologies and must adapt to the new ways in which people, machines, services and data can interact.

This paper is concerned specifically with the importance of higher education in supporting the development of the skills and competencies required for the Industrial Internet of Things era. Currently, the pictures of Internet of Things, Industrial 
Internet of Things and Industry 4.0 are still quite blurry. Although IoT, IIoT and Industry 4.0 are closely related concepts, they cannot be interchangeably used. So far, there is no generally accepted definition for each of these terms and in an attempt to understand these concepts, this paper tries to clarify them. The literature in the field proposes several definitions, some of them being presented in a section of this paper. Next section provides a short comparison of IIoT and IoT. The IIoT development is being enabled by the improved availability and affordability of inexpensive (smart) sensors, processors, embedded systems, etc., but also by the developments in data storage, analytics, cloud infrastructure, and so on. Standardization plays an import role for the further development and spread of IIoT. In addition to listing the important IIoT enablers, we also highlight the opportunities and challenges brought forth by IIoT. The next section outlines some possible directions for future research and the paper ends with some concluding remarks.

\section{IOT, IIOT, INDUSTRY 4.0}

\section{A. IoT, IIoT and Industry 4.0 Concept Disambiguation}

The concepts of Internet of Things, Industrial Internet of Things and Industry 4.0 do not have precise and widely accepted definitions. The literature in the field proposes several of them, some being presented in the following paragraphs.

Internet of Things:

- is "enabling advanced services by interconnecting (physical and virtual) things based on existing and evolving interoperable information and communication technologies" [6].

- "is not a single technology; rather it is an agglomeration of various technologies that work together in tandem" [7].

The Industrial Internet of Things, viewed as an industrial adaptation of the Internet of Things, has many naming variations - "Industrial Internet" as GE terms it, "Internet of Everything" term proposed by Cisco, Rockwell Automation's "IoT Industrial Revolution", IBM's "Smarter Planet" or the European "Industry 4.0" or "Industrie 4.0" (original German term), respectively French "Industrie du Futur" (Industry of the Future). The term Industrial Internet of Things (abbreviated as IIoT, I-IoT, I2OT or I2oT) is used to represent what is expected to revolutionize the industry, by merging the digital and real industry [8]. The Industrial Internet of Things is defined as follows:

- "a universe of intelligent industrial products, processes and services that communicate with each other and with people over a global network" [9].

- "is a distributed network of smart sensors that enables precise control and monitoring of complex processes over arbitrary distances" [10].
Industry 4.0 or Industrie 4.0:

- "focuses on the end-to-end digitisation of all physical assets and processes as well as integration into digital ecosystems with value chain partners" [11].

According to [12], the Industrial Internet of Things is related with Industry 4.0: "all Internet of Things applications in Industry 4.0 are forms of IIoT, but not all IIoT use cases are about the industries which are categorized as Industry 4.0”.

In many cases, the terms Industry 4.0 and Industrial Internet of Things are used interchangeably [13], despite the differences between them. But, according to [14], "Industrial IoT and Industry 4.0 essentially have a cause-and-effect relationship. That is, the Industrial IoT is the basis for, and will result in, the fourth industrial revolution". Industry 4.0 or i-4.0 initiative is focused specifically on the manufacturing industry and ensuring its competitiveness in a dynamic global market. The IIoT concept is "more focused on enabling and accelerating the adoption of Internet-connected technologies across industries, both manufacturing and non-manufacturing" [15]. In fact, IIoT is viewed as a key enabler for the 4th industrial revolution (IR 4.0).

The term coined by the addition of the fourth letter, "I" in front of IoT describes the new concept, IIoT. There are some common points between these concepts, IoT and IIoT, but there are also notable differences, some of which are being presented in the next section of this paper.

\section{B. Industrial Internet of Things vs. Internet of Things}

Although the Industrial IoT follows the same core definition of the IoT and share some common characteristics (Table 1), these paradigms are also distinguished by different features (Table 2).

TABLE I. IOT VS. IIOT - SIMILAR CHARACTERISTICS

\begin{tabular}{|l|l|}
\hline Perspective & Internet of Things and Industrial Internet of Things \\
\hline $\begin{array}{l}\text { Availability of } \\
\text { connected } \\
\text { devices }\end{array}$ & $\begin{array}{l}\text { availability of affordable and intelligent devices; } \\
\text { connectivity brings the true value of IoT and IIoT, } \\
\text { ensuring monitoring, control, etc.; although they are used } \\
\text { to reach different goals }\end{array}$ \\
\hline $\begin{array}{l}\text { Architecture } \\
\text { Technologies }\end{array}$ & $\begin{array}{l}\text { [Collect | Store | Analyze | Share] architecture } \\
\text { sloud computing, communication technologies, (smart) } \\
\text { machine learning, etc. }\end{array}$ \\
\hline Challenges & $\begin{array}{l}\text { interoperability, security and privacy protection, skill } \\
\text { shift for users, lack of experience and expertise for } \\
\text { developers, acceptance, capital }\end{array}$ \\
\hline
\end{tabular}


TABLE II. IOT VS. IIOT - DIFFERENT CHARACTERISTICS

\begin{tabular}{|l|l|l|}
\hline Perspective & Internet of Things & $\begin{array}{l}\text { Industrial Internet of } \\
\text { Things }\end{array}$ \\
\hline $\begin{array}{l}\text { Connected } \\
\text { things }\end{array}$ & $\begin{array}{l}\text { consumer-level devices, } \\
\text { usually less expensive }\end{array}$ & $\begin{array}{l}\text { critical machines, sensors, } \\
\text { systems, usually with a high } \\
\text { degree of complexity }\end{array}$ \\
\hline Service model & human-centric & machine-centric \\
\hline Applications & $\begin{array}{l}\text { consumer-oriented } \\
\text { applications }\end{array}$ & industry-oriented applications \\
\hline $\begin{array}{l}\text { Communication } \\
\text { infrastructure }\end{array}$ & essentially wireless & wireless and wired \\
\hline $\begin{array}{l}\text { Communication } \\
\text { capabilities }\end{array}$ & $\begin{array}{l}\text { a small number of } \\
\text { standards }\end{array}$ & $\begin{array}{l}\text { a high number of } \\
\text { connectivity standards and } \\
\text { technologies }\end{array}$ \\
\hline Amount of data & medium to high & high to very high \\
\hline Criticality & not stringent & $\begin{array}{l}\text { mission critical (timing, } \\
\text { reliability, security, privacy) }\end{array}$ \\
\hline $\begin{array}{l}\text { Real-time } \\
\text { requirement }\end{array}$ & $\begin{array}{l}\text { usually no, dealing with } \\
\text { less time-sensitive } \\
\text { systems }\end{array}$ & most often has a key role \\
\hline
\end{tabular}

\section{Industrial Internet of Things Enablers, Benefits and Challenges}

There are various IIoT enablers: software and hardware technologies; business organization and culture; standardization; public policy; skilled human resources, detailed in Fig. 1. Thus, for example, in order to implement flexible, customizable, and efficient industrial systems, completely aligned with the IIoT concepts, all related enabling technologies (industrial networks, cloud computing, big data, artificial intelligence, data analytics, blockchain, etc.) and hardware systems (embedded systems, industrial robots, etc.) must be equally developed for being integrated into IIoT systems [16].

IIoT platforms have played and will play an important role in supporting the development and implementation of IIoT applications, by reducing the complexity of various phases of the application lifecycle like, for example, development, deployment, etc. Currently, there are more IIoT platforms available [17]. As IIoT becomes better defined and continues to grow and to be further developed, more impactful and powerful IIoT applications can and will be created and deployed; development of these applications may or may not use an IIoT platform.

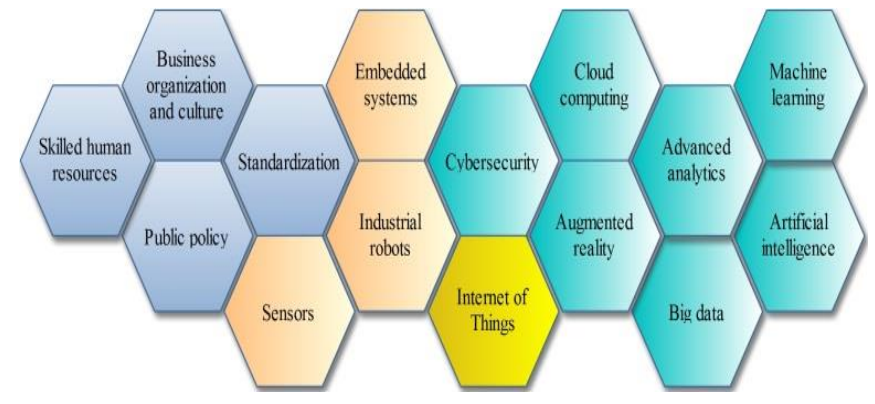

Fig. 1. IIoT Enablers.
IIoT could bring various benefits in an industrial context, some of the key ones being the following: monitoring production flow and inventory; enhancing automation, productivity, industrial safety, efficiency, security and quality control; enabling easy maintenance, inventory management, products tracking and tracing, development of new business models, services and/or products; optimization of packaging, logistics and supply chain; reduction of human errors and manual labor, and of costs (both in terms of time and money), etc.

Besides all the benefits, the large-scale deployment of IIoT is beset with various challenges. The key challenges "stem from the requirements in energy-efficient operation, real-time performance in dynamic environments, the need for coexistence and interoperability, maintaining the security of the applications and users' privacy" [18], establishing connectivity, lack of standardization, etc. Besides technical challenges, there are broader social, economic and political enabling factors that have to be overcome. Thus, the adoption of the Internet of Things paradigm in the industrial field is delayed by the socalled skills gap. The literature reports that currently, Industrial Internet of Things represents a cornerstone of many companies' business strategies. Also, many agreed that rapidly developing IIoT will have significant and far-reaching effects on the industrial and market sectors, transforming and redefining virtually all markets and industries; the effects will also generate changes in other fields, such as education.

\section{IIOT HIGHER EDUCATION}

In order to address higher education in the context of the Industrial Internet of Things, we have in view a holistic view of all IIoT-related higher education perspectives from:

- A scientific perspective - universities are conducting research both in the IIoT field and the IIoT-related fields, thus contributing to the expansion of knowledge horizons;

- An educational perspective - through their teaching, universities actively support the dissemination of IIoT know-how amongst students and graduates, thus improving the stock of skilled human capital;

- A technological perspective - universities support the transfer of their know-how to industry, by focusing on technology transfer.

Next, we are trying to present some aspects of IIoT higher education, by taking into account the above mentioned dimensions.

\section{A. The Scientific Perspective}

In recent years, there has been a growing interest in Industrial Internet of Things and IIoT, as Google Trend shows (Fig. 2). We can visualize the relative popularity of these keywords between 2008 and 2018.

Moreover, the number of publications that addressed Industrial Internet of Things is quickly growing. Some of these publications present the findings of the research carried out in universities. In order to summarize the current status of scientific publications on the use of IoT in industries, the 
authors of this paper carry out an extensive literature review by examining important articles from six relevant academic databases (Web of Science, IEEE Xplore, ScienceDirect, SpringerLink, Scopus, ACM digital library). As a result, we found a large number of journal articles and conference papers, books and book chapters related to the existing IIoT research. For example, we found 453 IIoT-related scientific articles and books/chapters published from 2011 to 2018 just by searching the Web of Knowledge database. We also identified the publications where at least one author has an academic affiliation. Fig. 3 displays the number of scientific publications stored in the above-mentioned databases, by taking into consideration two categories for author's affiliation: academic and non-academic. The figure highlights the noticeably growing trend of IIoT research in the recent years and as well as the important role played by academic authors.

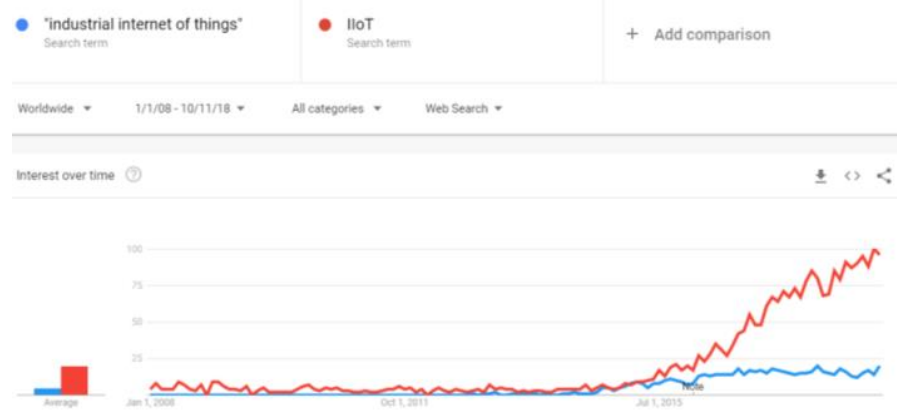

Fig. 2. Search Volume Index for the Data Provided by Google Trends Corresponding to the Industrial Internet of Things and IIoT Search Terms.

TABLE III. THE NUMBER OF SCIENTIFIC PUBLICATIONS ON INDUSTRIAL INTERNET OF THINGS

\begin{tabular}{|l|l|l|l|l|l|l|}
\hline Search & $\begin{array}{l}\text { Web of } \\
\text { Science }\end{array}$ & IEEE & $\begin{array}{l}\text { Science } \\
\text { Direct }\end{array}$ & $\begin{array}{l}\text { Springer } \\
\text { Link }\end{array}$ & Scopus & $\begin{array}{l}\text { ACM } \\
\text { digital } \\
\text { library }\end{array}$ \\
\hline $\begin{array}{l}\text { Industrial } \\
\text { Internet } \\
\text { of Things }\end{array}$ & 453 & 461 & 63 & 442 & 725 & 23 \\
\hline $\begin{array}{l}\text { Industrial } \\
\text { Internet } \\
\text { of Things } \\
\text { and } \\
\text { academic } \\
\text { affiliation }\end{array}$ & 187 & 316 & 50 & 397 & 509 & 16 \\
\hline
\end{tabular}

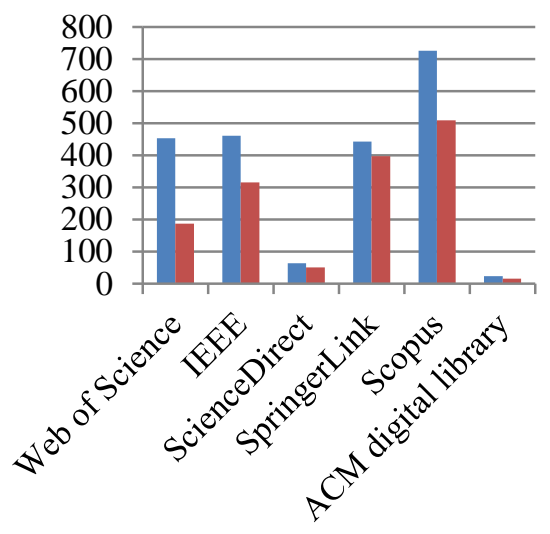

- Industrial

Internet of Things

\section{- Industrial Internet of Things and academic affiliation}

Fig. 3. Number of Scientific Publications Related to the IIoT.

\section{B. The Educational Perspective}

Secondly, we have in view the educational dimension of the IIoT Higher Education.

Various worldwide studies, reports and scientific papers reveal the fact that the biggest challenge of the Industrial Internet of Things supporters is not so much technology itself but the people. While digital technologies are rapidly becoming a commodity, success largely depends on an organization's Digital IQ [19]. Therefore, it is critical to improve the digital skills of the employees who need to roll out digital processes and service [20].

Based on the existing trends, experts predict that profound changes starting from the content to the delivery within the Internet of Things and Industrial Internet of Things are needed in regards to the main aspects of education. In order to meet the changing requirements and respond to the increasing demand for a future highly skilled workforce, new effective educational programmes will have to be improved or developed and/or the existing academic curricula will have to be re-structured. Furthermore, higher education institutions have to overcome the traditional way of learning, by embracing the latest technologies in order to innovate the learning process. According to [21], workers who are skilled at developing and deploying IIoT systems will find themselves in greater demand. Digital competences and innovation are widely considered to be some of the key drivers to boost the competitiveness of companies within the IIoT context. In this respect, disruptive technologies, such as those listed in the previous section, which have been leveraged for the development of IIoT, should be viewed as building blocks for the basis of a curriculum adjusted to meet the IIoT's requirements. Furthermore, according to the recommendations of various studies and reports, universities must equip students with attributes that will enable them to respond to an uncertain future - by "handling ambiguity, emotional intelligence, adaptability" [22]. It is a fact that the focus on the technical development of the individual is just a part of the IIoT's educational vision. According to [23], "the ongoing reorganization and realignment of education systems" will also be of a paramount importance.

The transition from higher education towards employment is a challenge that could be more easily addressed through the efforts of both universities and employers, as part of universities-employers partnerships. In fact, the importance of employer-university relationships is also supported by the graduate employment rate as a key performance indicator for universities. Consequently, universities have increased their focus both on supporting the employability rate of students and graduates, and on their partnership with the business and industry sectors. The purpose is twofold: to prepare students for the labor market as well as to increase the graduate employment rates. In fact, some universities have to work harder and in more innovative ways to attract potential employers. A solution that has highly been used in the recent years is to involve the private sector in developing the academic curricula, based on specific needs. Moreover, placements and internships in various companies give students a chance to gain work experience. 
Yet, as experts point out, the current approaches regarding the Industrial Internet of Things education and training do not rise up to the challenge [24]. Thus, in order to shape up an enhanced environment for Industrial IoT education, the training needs in different domains have to be investigated in a more detailed manner. Academic and Higher Vocational Education and Training (HVET) programs, work-based education, virtual and remote laboratories for educational purposes, national and international educational policies and tools, extensions, etc. should be considered.

\section{The Technological Perspective}

No doubt that the progress made in the field of IIoT technologies has and certainly will have the potential to transform the industrial sector. Industrial Internet of Things is a concept with a high level of innovation. Over the past few years, we have seen many innovations that have been designed as solutions to the new challenges posed by the IIoT and Industry 4.0. Yet, technology transfer is essential for imparting the information and adapting these innovations to real life situations. Technology transfer is defined by the Association of University of Technology Managers (AUTM) as "the process of transferring scientific findings from one organization to another for the purpose of further development and commercialization". Worldwide, there is a large number of studies that tackle the university technology transfer process.

The active academic technology transfer could be of service to a university, the region and the country, industry partners, and the public in a numbers of ways. Some of them have been revealed in an extensive number of scientific papers and studies. Thus, for example, we could mention the article from the National Academy of Inventors that attempts to examine the importance of "technology transfer" for universities [25].

Without simplifying the overall technology transfer process from the point of view of the variety of activities that technology transfer process encompasses, the present study focuses solely on patenting in relation to the Industrial Internet of Things within the Fourth Industrial Revolution.

Based on the latest available information on patent applications on the Fourth Industrial Revolution that has been available until 2016, the European Patent Office (EPO) conducted a landscaping study on "Patents and the Fourth Industrial Revolution (4IR)" [26], by providing a first cartography of this dynamic technological field based on patent activity. According to this study, "European patent applications related to smart connected objects are rising rapidly, achieving a growth rate of 54\% in the last three years" [26]. The EPO report reveals that despite the fact that the growth rate of patent applications in this field is higher than in any other field of technology and is increasing at a fast rate, the patent applications still represent a relatively modest percentage of all European patent applications (only 3,3\%). Moreover, the 25 biggest 4IR applicants for the EPO in between 2011-2016 are large, traditionally ICT-focused companies.

In order to support IIoT innovation with quality patents, universities must focus their efforts in this direction and encourage sharing the results gathered by their own researchers through licensed patents. In addition, besides stimulating students' creativity, providing students with patenting skills is very important. Academic inventions and technology transfer could bring significant benefits to students, by providing them opportunities "to participate in real-world translational research, gain experience in the process of obtaining a patent, and work with industry, start-ups, and manufacturers" [25].

\section{FUTURE RESEARCH}

As changes in higher education take time, all stakeholders will now have to act in preparing for the Industrial Internet of Things. An analysis regarding the Industrial Internet of Things higher education should also take into consideration other aspects, which have not been presented in this paper, due to space limitations. A comprehensive study on how to develop an IIoT education system should consider and address existing approaches, the skills required and also the appropriate contexts. New digital workforce models could be developed. Also, the study should focus heavily on all the educational activities related to IIoT, including academic and Higher Vocational Education and Training (HVET) programs, workbased education, virtual and remote laboratories for didactic educational purposes, but also national and international educational policies and tools, etc. Alongside the realignment of university curricula, the main findings should focus on a comprehensive strategy, to develop good practices and recommendations to reform education so that it becomes more responsive to the requirements of the future workforce; the purpose is to further build and strengthen the collaboration between education and the labor market, in order to consolidate future employment trends.

\section{CONCLUSIONS}

This paper is aimed to examine the 'Industrial engineering education', focusing on the adoption of the Internet of Things in industry (Industrial Internet of Things) and the requirements for higher education in the times of the fourth industrial revolution.

The pictures of Internet of Things, Industrial Internet of Things and Industry 4.0 are still quite fuzzy. Because these concepts have no precise and widely accepted definitions, we presented some considered relevant by scientific literature. The paper also highlights the most important similarities and differences between these concepts.

IIoT can bring important benefits to companies in all types of industries. To seize the opportunities brought forth by IIoT, several obstacles would need to be overcome. Thus, for example, besides focusing only on the technical issues, the relationships between all stakeholders, from individuals to organizations, and from businesses to governments, must also be taken into consideration. Over the coming years, business and governments must intensify their efforts and escalate investments, but also must change their approach to education, skills and employment. Higher education must also intensify efforts aimed at tackling skills gaps and it must take additional measures in order to anticipate and address in a timely manner the issues related to the potential large-scale transformations of the employment landscape and the 'holistic' nature of skills requirements. In this respect, developing stronger employer- 
university ties for internships, training needs assessment, etc. is a valuable strategy needed to be encouraged and extended in the near future.

\section{ACKNOWLEDGMENT}

This work was partially supported from the project "Integrated Center for research, development and innovation in Advanced Materials, Nanotechnologies, and Distributed Systems for fabrication and control", Contract No. 671/09.04.2015, Sectoral Operational Program for Increase of the Economic Competitiveness co-funded from the European Regional Development Fund.

\section{REFERENCES}

[1] Daugherty, P., Berthon, B., Winning with the Industrial Internet of Things: How to Accelerate the Journey to Productivity and Growth, Dublín: Accenture, 2015.

[2] MRS Research Group. Global Industrial Internet of Things (IIoT) Market 2017 - Production, Sales, Supply, Demand, Analysis \& Forecast to $2021,2017$.

[3] Manyika, J., Chui, M., Bisson, P., Woetzel, J., Dobbs, R., Bughin, J., Aharon, D., The Internet of Things: Mapping the value beyond the hype, McKinsey \& Company, San Francisco, 2015, Available at: https://www.mckinsey.com/.

[4] *, The future of jobs: Employment, skills and workforce strategy for the fourth industrial revolution. In World Economic Forum, 2016.

[5] Giffi, C., McNelly, J., Dollar, B., Carrick, G., Drew, M., Gangula, B., The skills gap in US manufacturing: 2015 and beyond, Washington, DC: Deloitte and Manufacturing Institute, 2015.

[6] *, Internet of Things Global Standards Initiative. International Telecommunications Union, 2012.

[7] Sethi, P., Sarangi, S. R. Internet of things: architectures, protocols, and applications. Journal of Electrical and Computer Engineering, 2017.

[8] Hartmann, M., Halecker, B., Management of innovation in the industrial Internet of Things. In ISPIM Conference Proceedings (p. 1). The International Society for Professional Innovation Management (ISPIM), 2015.

[9] Banerjee Prith, Industrial Internet of Things Poised to Drive Unconventional Growth, 2014.

[10] Huberman, B. A., Ensuring Trust and Security in the Industrial IoT: The Internet of Things (Ubiquity symposium), 2016.
[11] "Industry 4.0: Building the digital enterprise", PwC, 2016.

[12] *, The Internet of Things (IoT) - essential IoT business guide, i-Scoop 2016, Available at: https://www.i-scoop.eu/internet-of-things-guide/

[13] Kagermann, H., Helbig, J., Hellinger, A., Wahlster, W, Umsetzungsempfehlungen für das Zukunftsprojekt Industrie 4.0: Deutschlands Zukunft als Produktionsstandort sichern; Abschlussbericht des Arbeitskreises Industrie 4.0. Forschungsunion, 2013.

[14] Albert, M. (2015). Seven things to know about the internet of things and industry 4.0. Modern Machine Shop, 88(4), 74-81.

[15] De Bernardini Luigi, Industry 4.0 and IIoT: different approaches to a smarter industry, 2016.

[16] Wan J., Lai C.F., Song H., Imran M., Jia D., Software-Defined Industrial Internet of Things, Wireless Communications and Mobile Computing, 2018.

[17] *, Industrial Internet of Things Market Analysis 2018 To 2022. Market Research Future, 2018.

[18] Sisinni, E., Saifullah, A., Han, S., Jennehag, U., \& Gidlund, M. (2018). Industrial Internet of Things: Challenges, Opportunities, and Directions. IEEE Transactions on Industrial Informatics, 1-1. https://doi.org/10.1109/TII.2018.2852491

[19] PwC, Global Digital IQ Survey. PriceWaterHouse Coopers. September 2015.

[20] PwC, 2017 Global Digital IQ Survey: A decade of digital. Keeping pace with Transformation, 10th anniversary edition, PriceWaterHouse Coopers, 2017.

[21] Manyika, J., Chui, M., Bisson, P., Woetzel, J., Dobbs, R., Bughin, J., \& Aharon, D., Unlocking the Potential of the Internet of Things. McKinsey Global Institute, 2015, Available at: https://www.mckinsey.com/.

[22] Edmondson M., Ward A., Tackling the disconnect between universities, Small businesses and graduates in cities and regions. Gradcore, 2017

[23] Broadband, Working Group on Education: Digital skills for life and work, Broadband Commission Working Group on Education, September 2017.

[24] O'Halloran, D., Kvochko, E., Industrial internet of things: unleashing the potential of connected products and services. In World Economic Forum (p. 40), 2015.

[25] McDevitt, V. L., Mendez-Hinds, J., Winwood, D., Nijhawan, V., Sherer, T., Ritter, J. F., Sanberg, P. R., More than money: The exponential impact of academic technology transfer. Technology \& Innovation, 16(1), 75-84, 2014.

[26] EPO, Patents and the Fourth Industrial Revolution. European Patent Office, Handelsblatt Research Institute. Available at: https://www.epo.org/service-support/publications.html?pubid=163\#tab3 